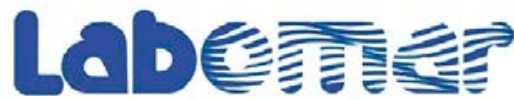

Arquivos de Ciências do Mar

\section{CULTIVO DE CAMARÕES EM SISTEMA DE BIOFLOCOS NO BRASIL: UMA ALTERNATIVA SUSTENTÁVEL ȦS INTENSIFICAÇÕES NA AQUICULTURA}

\author{
Shrimp farming in biofloc system in Brazil: \\ a sustainable alternative to intensification in aquaculture
}

\author{
Bruna Bitencourt da Costa ${ }^{1 *}$, Danilo Pedro Streit Júnior ${ }^{1}$ \\ *bruna.bitencourt@ufrgs.br \\ ${ }^{1}$ Programa de Pós-graduação em Zootecnia. Universidade Federal do Rio Grande do Sul. \\ Faculdade de Agronomia. Avenida Bento Gonçalves, 7712 Porto Alegre.
}

\begin{abstract}
RESUMO
O crescimento da aquicultura e a crescente demanda por alimentos de origem animal, aliado às novas exigências dos consumidores, vêm fazendo com que aumente a preocupação destes com a contaminação ao ambiente devido à execução da atividade, o que motiva técnicos e pesquisadores a buscarem novas alternativas mais sustentáveis para a produção animal. Assim, esta revisão foi realizada com o objetivo de debater os principais aspectos em relação à carcinicultura e à tecnologia de bioflocos (BFT) empregada neste sistema. Pesquisas estão sendo desenvolvidas na área, visando aprimorar as técnicas e estabelecer novas metodologias, e apresentam resultados satisfatórios em todas as fases do ciclo de produção. Este trabalho apresenta resultados obtidos pelo uso do sistema BFT, tanto para as características de desempenho, como para as características de qualidade da água e saúde relacionadas à carcinicultura.
\end{abstract}

Palavras-chaves: bioflocos, camarão, BFT, carcinicultura, qualidade da água.

\section{ABSTRACT}

The progress of aquaculture and the growing demand for food of animal origin, coupled with the new demands of consumers, have been increasing their concern with the environment contamination due to the implementation of the activity, what motivates technicians and researchers 
to seek new alternatives for a more sustainable animal production. Thus, this review was carried out to discuss the principal aspects related to shrimp farming and biofloc technology (BFT) used in this system. Research is being developed in the area, aiming to improve the techniques, establish new methodologies and present satisfactory results at all stages of the production cycle. This paper presents results obtained using the BFT system, both for performance characteristics as to the water quality characteristics and health related to shrimp farming.

Key words: biofloc, shrimp, BFT, shrimp farming, water quality.

\section{INTRODUÇÃO}

A aquicultura é o segmento do agronegócio que tem apresentado o maior crescimento entre os setores da produção de alimentos de origem animal. Segundo FAO (2016), mundialmente a pesca somada à aquicultura totalizaram, em 2014, 167,2 milhões de toneladas (93,4 milhões de toneladas oriundas da pesca e 73,8 milhões de toneladas oriundas da aquicultura). Com a estagnação da pesca, desde o final da década de 80, e a crescente demanda por pescado, a aquicultura vem expandindo sua produção, sendo responsável pelo crescimento da oferta de pescado para consumo humano, demonstrando um grande potencial de geração de renda e desenvolvimento regional (FAO, 2016). Esta atividade tem apresentado um crescimento médio anual de $8,8 \%$, enquanto a pesca, desde a década de 70 , tem apresentado crescimento de apenas 1,2\% ao ano. O Brasil é o segundo maior produtor das Américas, com uma produção em 2014 de 561,8 mil toneladas de pescado (FAO, 2016), perdendo apenas para o Chile.

Entre as diferentes modalidades aquícolas, a carcinicultura vem se destacando no setor devido ao alto valor econômico do camarão no mercado. O cultivo de camarões marinhos representou 55\% da produção mundial de crustáceos em 2010, sendo o Litopenaeus vannamei a espécie mais produzida, superando 2,5 milhões de toneladas (FAO, 2012). Segundo FAO (2016), as capturas mundiais de camarão estão estáveis desde 2012 (em 3,5 milhões de toneladas) e atualmente o camarão é o segundo produto mais importante em termos de valor, possibilitando o crescimento da carcinicultura para suprir as demandas mundiais de camarão.

No Brasil, esta atividade teve início na primeira metade dos anos 70 com a espécie Penaeus japonicus em Pernambuco e no Rio Grande do Norte (Sampaio et al., 2010). No entanto, devido à inadaptabilidade desta espécie às condições ambientais brasileiras, uso de tecnologias inadequadas e às condições climáticas do país, o cultivo não obteve sucesso (Natori, 2011; Gaona et al., 2011). Somente no final dos anos 80, com a introdução de uma espécie exótica, o L. vannamei, com excelente adaptabilidade às variáveis ambientais brasileiras, iniciou-se estudos mais aprofundados e investimentos no desenvolvimento da carcinicultura. Após este período de experimentações, em meados da década de 1990, pôde-se observar um maior crescimento da atividade no Brasil e a partir deste período passou-se a dispor de rações de boa qualidade no mercado, além do domínio do ciclo de reprodução pelos laboratórios nacionais e produção de pós-larvas (Krumenauer, 2008; Sampaio et al., 2010; Furtado et al., 2011).

As principais espécies utilizadas na carcinicultura brasileira pertencem à família Penaeidae e estão divididas em seis gêneros: Farfantepenaeus, Fenneropenaeus, Litopenaeus, 
Marsupenaeus, Melicertus e Penaeus. O L. vannamei, destaca-se devido à suas características adaptabilidade e de sua alta capacidade produtiva, além do desenvolvimento da tecnologia de produção da espécie. No entanto, algumas espécies nativas do gênero Farfantepenaeus, entre elas o F. brasiliensis e F. paulensis, que se apresentam como alguns dos principais recursos pesqueiros explorados na costa brasileira, têm sido pesquisadas e possuem potencial para a cultura (Lopes et al., 2009; Viau et al., 2013; Souza et al., 2014).

Até a década de 1980, a carcinicultura brasileira utilizava práticas de um sistema extensivo, caracterizado pela necessidade de constantes renovações da água para manutenção da qualidade da mesma no sistema de cultivo (Burford et al., 2003). Estas constantes renovações geram uma grande quantidade de efluentes, com resíduos procedentes do sistema de cultivo, que podem provocar grandes impactos ambientais, além do elevado custo de produção. Os problemas ambientais ocorrem devido as altas concentrações de fósforo e nitrogênio nas águas de cultivo, que induzem o crescimento de algas, causando a eutrofização das águas naturais (Wang et al., 2016). Frente a estas questões e visando a redução da liberação destes efluentes, tem-se buscado novas estratégias e tecnologias que possibilitem uma aquicultura mais sustentável, ambientalmente e economicamente (Burford et al., 2003; Wasielesky et al., 2006).

Assim, estratégias de cultivo com mínima ou nenhuma renovação de água, com base na produtividade natural, estão sendo desenvolvidas com excelentes resultados, destacando-se: produtividade, custos de produção, redução do risco de introdução e da disseminação de doenças, redução dos efluentes aquícolas e otimização do consumo de água (Avnimelech, 1999, 2009; Burford et al., 2003; Wasielesky et al. 2006; Emerenciano et al., 2013; Panigrahi et al., 2018). A tecnologia de bioflocos (BFT), caracterizada pela presença de flocos microbianos e pelo cultivo de organismos aquáticos em altas densidades de estocagem sem renovação de água, tem se mostrado uma alternativa bastante eficiente, pois não somente reduz o uso de água, mas também a emissão de efluentes no meio ambiente evitando o dano ambiental (Burford et al., 2003; Hargreaves, 2006; Wasielesky et al., 2006; Avnimelech, 2015; Ahmad et al., 2017; Panigrahi et al., 2018). Esta tecnologia ganhou atenção recentemente como um método de aquicultura sustentável que controla a qualidade da água (Avnimelech, 2015; Ahmad et al., 2017). O uso deste sistema na produção de camarão marinho tem sido extensivamente estudado (Emerenciano et al. 2011, 2013; Ray et al. 2011; Silva et al. 2013; Schveitzer et al. 2013; Souza et al., 2014).

\section{O SISTEMA DE BIOFLOCOS}

O cultivo em sistema de bioflocos caracteriza-se por viveiros altamente oxigenados, com altas densidades de estocagem e elevada produtividade, com mínima ou nenhuma renovação de água, e fertilizados com fontes ricas em carbono para estimular o desenvolvimento de uma biota bacteriana predominantemente heterotrófica (Avnimelech, 1999; Krummenauer et al., 2011; Emerenciano et al., 2013). Enquanto em sistemas tradicionais de cultivo se consome em média $64.000 \mathrm{~L}$ de água para produzir $1 \mathrm{~kg}$ de camarão, no sistema de bioflocos são utilizados apenas $160 \mathrm{~L} / \mathrm{kg}$, o que permite uma redução significativa no consumo de água (Krummenauer, 2008; Gaona et al., 2011). Segundo Poersch et al. (2012a), o sistema BFT em cultivos de camarões pode ser uma alternativa viável para fazendas contaminadas com o vírus da mancha branca. Acredita-se que os flocos microbianos atuam contra os organismos patogênicos, através da competição por espaço, substrato e nutrientes, limitando seu desenvolvimento. 
Os bioflocos são compostos por microalgas, ciliados, flagelados, protozoários, rotíferos, saprófitas (organismos que obtêm nutrientes de matéria orgânica morta), bactérias nitrificantes e bactérias patogênicas (Vibrio spp), exoesqueletos, restos de organismos mortos, fezes, etc. (Wasielesky et al., 2006; Manan et al., 2017). Todos esses microrganismos têm sua própria função e interação no sistema (Manan et al., 2017). Além de contribuírem para a manutenção da qualidade da água presente no sistema, servem como fonte suplementar na alimentação dos animais cultivados, melhorando a taxa de crescimento, a conversão alimentar e o ganho de peso (Wasielesky et al., 2006; Panigrahi et al., 2014); e estão associados a uma maior sobrevivência e crescimento de camarões (Burford et al., 2003; Wasielesky et al., 2006; Emerenciano et al. (2013). Dessa forma, permitem um aumento na densidade de estocagem, melhor aproveitamento dos nutrientes da dieta, redução da conversão alimentar, redução da quantidade de ração e dos níveis de proteína bruta da mesma, com uma consequente redução nos custos com alimentação e nas emissões de efluentes ricos em nutrientes (Wasielesky et al., 2006; Krumenauer et al., 2014). Autores relatam um potencial de ganho de alimento estimado pela aplicação da tecnologia de bioflocos de 10 a 20\% (Crab et al., 2007; De Schryver et al., 2008) devido à recuperação de nitrogênio do sistema de cultura. Ao comparar as diferenças no crescimento e sobrevivência de L. vannamei em sistema de bioflocos versus sistema de recirculação de água clara, o peso corporal final, o coeficiente de crescimento diário e a sobrevivência foram significativamente maiores no sistema de bioflocos $(12,40 \mathrm{~g}, 5,0 \% \mathrm{~g} / \mathrm{d}$ e $87,1 \%$, respectivamente) do que no sistema de águas claras (7,0 g, 1,4\% g / d e 74,2\%) (Chan-Vivas et al., 2018).

Entre os microrganismos presentes neste meio, os de maior interesse são as bactérias heterotróficas. Estas possuem a capacidade de reciclar a matéria orgânica dentro do ambiente de cultivo, através da absorção dos compostos nitrogenados, e incorporá-los à biomassa microbiana, que fornece uma fonte suplementar de alimentação, reduzindo a demanda por proteína na ração (Burford et al., 2003; Wasielesky et al., 2006; Ballester et al., 2010; Souza et al., 2014). As bactérias heterotróficas utilizam o carbono orgânico e o nitrogênio inorgânico presente na água para produzir sua biomassa, removendo, assim, a amônia tóxica do sistema e reduzindo as renovações de água durante o cultivo (Avnimelech et al., 1999, 2009; Wasielesky et al., 2006; Ballester et al., 2010). A presença destas bactérias é importante no sistema de cultivo desde o início de sua implantação para evitar o desenvolvimento excessivo e a competição por substrato com as bactérias responsáveis pela oxidação da amônia. Estas bactérias oxidam a amônia a nitrito, que é extremamente tóxico, o que poderá causar prejuízos ao produtor pelo aumento da mortalidade e comprometimento no crescimento dos animais (Wasielesky et al., 2006).

Wasielesky et al. (2006a) observaram efeitos benéficos dos flocos microbianos no crescimento de L. vannamei, comprovando um ganho de peso adicional de até $32 \%$ associado a ingestão deflocos. Resultado similar foi observado por Ballester et al. (2010) em Farfantepenaeus paulensis. Estes trabalhos indicam que o bioflocos é uma fonte complementar de alimento aos camarões (Viau et al., 2013). Dietas suplementadas com bioflocos melhoram o desempenho reprodutivo em termos de fecundidade, desova e composição bioquímica de ovos em Farfantepenaeus duorarum e L. Vannamei (Emerenciano et al. 2012, 2014).

\section{MANEJO DO SISTEMA}

Segundo Ponce-Palafox et al. (1997), um fornecimento de água de boa qualidade é essencial para a aquicultura, sendo que os parâmetros de qualidade da água devem atender 
às necessidades ambientais da espécie a ser cultivada. Para que se tenha um bom desempenho no sistema BFT, as espécies necessitam ser resistentes a altas densidades de estocagem, tolerantes a níveis intermediários de oxigênio dissolvido, além de tolerar altos níveis de sólidos suspensos. Em sistemas de cultivo de camarões, a mesma deve ser monitorada frequentemente a fim de evitar o insucesso da atividade, visto que esta é uma característica variável, que muda ao longo do tempo como resultado de processos biológicos (fotossíntese, respiração e a excreção de resíduos metabólicos), fatores ambientais (temperatura e vento) e manejo do cultivo (excesso de alimentação). A qualidade da água pode afetar o hábito alimentar, o crescimento, a saúde e a sobrevivência dos animais nos viveiros (Ponce-Palafox et al., 1997; Pinheiro \& Filho et al., 2007). Uma água de boa qualidade favorece o crescimento dos camarões, além de reduzir a necessidade de trocas e renovações da mesma, o que minimiza o impacto de efluentes em corpos de água adjacentes (Campos et al., 2007).

O princípio básico do sistema BFT é a mínima ou nenhuma renovação de água e o estímulo do crescimento de comunidades microbianas específicas, através da manipulação da relação carbono e nitrogênio do sistema (Avnimelch, 1999; Wasielesky et al., 2006; Emerenciano et al., 2013). Assim, as técnicas de manejo visam a manipulação da comunidade microbiana, visando controlar a qualidade da água pela imobilização da amônia em proteína microbiana, reciclando os resíduos da ração e incrementando a eficiência alimentar (Avnimelech, 2009), a fim de propiciar baixas concentrações de amônia e nitrito no meio de cultivo (Avnimelech, 1999; Burford et al., 2003; Wasielesky et al., 2006).

Desta forma, o controle dos sistemas de aeração, fertilização, alimentação, controle de sólidos suspensos totais é de extrema importância para o funcionamento adequado deste sistema. Os principais parâmetros a serem monitorados são: temperatura, oxigênio dissolvido, salinidade, $\mathrm{pH}$, alcalinidade e compostos nitrogenados.

\section{Temperatura}

Segundo Arana (2002), a temperatura é o parâmetro físico mais observado devido à sua facilidade de registro. É extremamente importante para o sistema de cultivo, pois influencia o metabolismo do crustáceo, limitando processos biológicos e a distribuição ecológica das espécies (Arana 2002). A temperatura ideal para a carcinicultura situa-se entre 25 $-32^{\circ}$ C. Ponce-Palafox et al. (1997) determinaram que a melhor sobrevivência e crescimento para juvenis de L. vannamei ocorre entre de 28 a $30^{\circ} \mathrm{C}$ em salinidade de 33 a $40 \%$.

Mudanças na temperatura da água podem influenciar a sobrevivência, a muda e a fisiologia dos camarões, podendo causar supressão imunológica e suscetibilidade a patógenos (Hewitt \& Duncan, 2001; Coman et al., 2002; Wang \& Chen, 2006). Por exemplo, o estresse térmico prejudicou a barreira intestinal de L. vannamei por danificar a estrutura da mucosa, induzindo estresse oxidativo e comprometendo o estado imunológico e metabólico (Duan et al., 2018).

\section{Oxigênio dissolvido}

O oxigênio é o parâmetro mais crítico do sistema de cultivo, sendo recomendadas concentrações de oxigênio dissolvido entre 5 - $10 \mathrm{mg} / \mathrm{L}$ (Arana, 2002). Níveis críticos de oxigênio dissolvido são extremamente prejudiciais ao sistema, pois comprometem a sobrevivência e o crescimento dos animais. Segundo Boyd \& Teichert-coddington (1992), em um 
sistema de bioflocos, as fontes de oxigênio são o fitoplâncton, oxigênio atmosférico (difusão) e oxigênio a partir dos aeradores mecânicos. Em altas densidades de estocagem, o consumo de oxigênio torna-se muito elevado, devido ao consumo dos camarões e também dos microrganismos presentes nos flocos microbianos, zooplâncton e respiração do fitoplâncton, e este tende a reduzir durante o ciclo de cultivo. Para um bom funcionamento deste sistema e manutenção das altas densidades de estocagem utilizadas, é necessário um bom sistema de aeração suplementar (Burford et al. 2003; Emerenciano et al., 2013). A aeração se faz importante também para manter o material particulado em suspensão, distribuindo-o de forma mais homogênea na coluna d'água, e para a homogeneização das camadas do estrato superior, rico em oxigênio dissolvido, e inferior, geralmente mais pobre, favorecendo os processos microbianos e reduzindo as condições estressantes que limitam o crescimento dos camarões (Avnimelech \& Ritvo, 2003).No sistema de bioflocos, diferentes tipos de aeradores podem ser utilizados, de acordo com o tamanho e as necessidades do sistema de cultivo, entre eles, os sopradores radiais (blower), pedras porosas, difusores de ar (tubulares ou tipo prato), aeradores de pás (paddlewheels), entre outros (Arana, 2002). Lara et al. (2017) testaram diferentes aeradores no cultivo de L. vannamei, avaliando os efeitos sobre a qualidade da água, crescimento de camarão e composição do biofloco, concluindo que os difusores de ar tipo blower melhoram a formação do biofloco e o desempenho de L. vannamei.

\section{Salinidade}

A salinidade é uma medida da concentração total de íons inorgânicos dissolvidos na água e está relacionada aos processos de osmorregulação dos organismos aquáticos. Para camarões Peneídeos, os níveis de tolerância quanto à salinidade podem variar ao longo do ciclo de vida e de acordo com a espécie (Ponce-Palafox et al., 1997). Tais autores obtiveram os melhores resultados de sobrevivência e crescimento de juvenis de L. vannamei em salinidades entre 33 e 40\%o. Já Maicá et al. (2011) avaliaram o efeito da baixa salinidade na qualidade da água, composição dos flocos microbianos e desempenho de juvenis de L. vannamei. Estes autores observaram um melhor crescimento e sobrevida em uma salinidade de $25 \mathrm{~g} / \mathrm{L}$. Por outro lado, a produtividade neste estudo foi satisfatória em baixa salinidade ( $4 \mathrm{~g} / \mathrm{L})$, sugerindo a viabilidade da criação desta espécie nesta condição. Este mesmo fato foi comprovado por Ray \& Lotz (2017) que verificaram a viabilidade do cultivo de L. vannamei em baixa salinidade.

\section{pH e alcalinidade}

De acordo com Furtado et al. (2013), o pH é um parâmetro de extrema importância, pois tem influência em diversas reações químicas que ocorrem na água e sobre o equilíbrio e toxicidade de certas substâncias presentes na mesma, além de interferir em diversos processos fisiológicos dos camarões. Emerenciano et al. (2017) recomenda que o $\mathrm{pH}$ dos tanques de cultivo deve ser mantido na faixa de 6,8 a 8,0. Durante a formação do biofloco, ocorre uma diminuição da alcalinidade e do $\mathrm{pH}$, devido ao consumo de carbono inorgânico pelas bactérias autotróficas presentes no meio (Furtado et al., 2015). Nos sistemas de cultivo, ocorre uma variação nos valores de $\mathrm{pH}$ ao longo do dia em decorrência, principalmente, das variações dos níveis e assimilação de $\mathrm{CO}_{2}$, devido a respiração dos organismos presentes no tanque e a fotossíntese realizada pelo fitoplâncton (Arana, 2002; Furtado et al., 2013). 
Já a alcalinidade, está diretamente relacionada ao $\mathrm{pH}$, atuando como tampão nas variações diárias do mesmo (Arana, 2002; Furtado et al., 2013; Emerenciano et al. 2017). Segundo Furtado et al. (2011), é a capacidade da água manter o equilíbrio ácido-base e a manutenção de níveis adequados desta no ambiente de cultivo contribui para a moderação nas alterações de $\mathrm{pH}$, devendo esta ser maior que $100 \mathrm{mg} \mathrm{CaCO}_{3} / \mathrm{L}$. Furtado et al. (2015) avaliaram os efeitos de diferentes alcalinidades sobre a qualidade da água e o desempenho zootécnico de L. vannamei em BFT, concluindo que maiores alcalidades (150 e $300 \mathrm{mg} \mathrm{CaCO}_{3} / \mathrm{L}$ ) favorecem a formação de biofloco e o estabelecimento de bactérias nitrificantes.

\section{Compostos nitrogenados}

O principal produto de excreção dos organismos aquáticos é a amônia, composto resultante do catabolismo das proteínas, sendo a forma não ionizada $\left(\mathrm{NH}_{3}\right)$ a mais tóxica para os organismos aquáticos. Segundo Emerenciano et al. (2017) os valores máximos para estes compostos no cultivo de juvenis de L. vannamei são de $<1 \mathrm{mg} / \mathrm{L}$ para amônia não-ionizada, < $1 \mathrm{mg} / \mathrm{L}$ para nitrito e $0.5-20 \mathrm{mg} / \mathrm{L}$ para nitrato. Campos et al. (2012) estabeleceram os níveis de segurança de amônia, nitrito e nitrato para juvenis de F. brasiliensis em 0,88 mg/L, 10,60 mg/L e 91,21 mg/L, respectivamente.

A amônia é convertida a nitrato através do processo de nitrificação e este tem como intermediário o nitrito, que também é tóxico para os organismos aquáticos. A velocidade do processo de nitrificação varia de acordo com a temperatura e pH da água e também devido à presença das bactérias quimioautotróficas e heterotróficas Nitrosomonas e Nitrobacter (Arana, 2002). O nitrogênio amoniacal presente no sistema é formado a partir do excesso de alimento (ração) fornecido que não é consumido e pelas excretas dos animais (Furtado et al., 2011). No processo heterotrófico, a remoção do nitrogênio amoniacal ocorre pela incorporação em biomassa bacteriana, que é estimulada com a adição de carboidrato na água (Panigrahi et al. 2018). No sistema BFT, o objetivo é estimular a assimilação direta do nitrogênio pelo processo heterotrófico, sem que o processo de nitrificação feito pelas bactérias autotróficas ocorra (Wasielesky et al., 2006; Ballester et al., 2010). Para estimular o rápido crescimento das bactérias heterotróficas, é necessária uma relação C:N de 15-20 (Krumenauer et al., 2014; Ahmad et al., 2017). No estudo de Panigrahi et al. (2018) o crescimento médio diário e peso corporal médio de L. vannamei foi maior nos tratamentos com a relação C:N de 15 em comparação com os tratamentos com C:N 5, 10 e 20.

Para alcançar esta proporção, realiza-se a fertilização da água com fontes ricas em carbono orgânico, como melaço, dextrose, farelos de trigo e arroz, farinha de mandioca, entre outras (Froes et al., 2012). De acordo com Avnimelech (1999), a fonte de carbono serve como um substrato para o bioflocos. Para promover a formação dos flocos microbianos e balancear as proporções de C:N, Wasielesky et al. (2006) e Ballester et al. (2010) sugerem a utilização de melaço. $\mathrm{O}$ melaço atua como fonte de carbono favorecendo o desenvolvimento das bactérias heterotróficas e auxiliando na conversão do nitrogênio em proteína microbiana, sendo um instrumento efetivo no controle dos compostos nitrogenados, principalmente amônia e nitrito (Wasielesky et al., 2006; Krumenauer et al., 2014), reduzindo o tempo necessário para desenvolvimento do floco microbiano (Samocha et al., 2012). Souza et al. (2014) demonstraram que com uso de melaço como fonte de carbono em berçário de F. brasiliensis aumentou a sobrevivência, peso final e taxa de crescimento específico, além de menor concentração de Vibrio spp., quando comparado ao controle, sem adição de me- 
laço. Já Serra et al. (2015), concluíram que fontes de carbono de rápida de dissolução (melaço e dextrose) reduzem mais rapidamente as concentrações de amônia do que fontes de carbono de lenta degradação (farelo de arroz), porém com o farelo de arroz, obteve melhores resultados de desempenho zootécnico em engorda de L. vannamei.

\section{Densidade de estocagem}

A densidade de estocagem parece ser o critério mais limitante neste sistema de cultivo devido à forte influência na qualidade da água. Visto que o sistema de bioflocos possui elevados custos de implementação e de operação, o incremento das densidades de estocagem em níveis superintensivos têm sido explorados para maximizar a produção por unidade de área e diluição destes custos. No entanto, as altas densidades podem dificultar o manejo, pois comprometem a qualidade da água, principalmente, pelo aumento da matéria orgânica e das concentrações de oxigênio dissolvido (Arnold et al., 2006). O aumento excessivo das densidades de estocagem pode gerar perdas devido a redução do crescimento e da sobrevivência dos camarões, o que tem sido um grande desafio para os produtores. Inúmeras pesquisas indicam existir uma relação inversa entre a densidade de estocagem e desempenho dos camarões na aquicultura (Otoshi et al., 2007). Estas reduções ocorrem principalmente devido ao aumento da competição por espaço e alimento e pelo canibalismo (Preto et al., 2005; Krummenauer et al., 2006). Krumenauer et al. (2011) demostraram que a uma densidade de 300 camarões $/ \mathrm{m}^{2}$ apresentou melhor desempenho zootécnico na fase de engorda de L. vannamei. Já Silva et al. (2013) recomendaram uma faixa entre 292,8 a 337,9 camarões/ $\mathrm{m}^{2}$ e observou-se que mesmo se a qualidade de água for mantida igual, há efeito negativo entre densidade e crescimento dos camarões, indicando que esse efeito possa ser comportamental. Já Preto et al. (2005), determinaram que na fase de berçário de F. paulensis podem ser estocados até 400 pós-larvas $/ \mathrm{m}^{2}$.

\section{Sólidos em suspensão}

Quanto ao material particulado em suspensão na água, é necessário que haja um controle sobre a concentração destes. Segundo Gaona et al. (2011), o excesso de sólidos suspensos no sistema pode causar impactos negativos, como o aumento da demanda biológica de oxigênio e oclusão de brânquias dos animais cultivados, podendo comprometer índices de crescimento e sobrevivência. O autor indica a clarificação como um método prático para a remoção do excesso de sólidos suspensos na água. Este processo tem como característica a remoção de sólidos suspensos por ação gravitacional em que as partículas sedimentam na parte inferior da coluna de água. Segundo Avnimelech (2009), altas concentrações de sólidos suspensos totais (SST), acima de $500 \mathrm{mg} / \mathrm{L}$, podem influenciar tanto a qualidade da água como o desempenho dos camarões, sendo os níveis de segurança entre 200 e 500 mg/L (Avnimelech, 2009; Gaona et al., 2011; Emerenciano et al., 2017).

Gaona et al. (2011), utilizando um clarificador que correspondeu a 2,28\% do volume do tanque de cultivo, verificaram uma redução de 24,5\% dos SST, mantendo estes em 500 $\mathrm{mg} / \mathrm{L}$, além de um melhor desempenho zootécnico de L. vannamei. Já Ray et al. (2010) verificaram que o uso de câmaras de sedimentação para redução dos níveis de sólidos em suspensão contribuiu, significativamente, para uma melhor conversão alimentar, biomassa, crescimento e peso final do L. vannamei. O melhor desempenho (peso final, sobrevi- 
vência, conversão alimentar e produtividade) de L. vannamei foi vertificado para concentração de SST na faixa de 100 a $300 \mathrm{mg} / \mathrm{L}$ (Gaona et al., 2017). Probióticos e prebióticos

Para obtenção de bons resultados em sistemas intensivos e superintensivos, de alta densidade, torna-se necessário o uso de aditivos, como probióticos, que são microrganismos vivos suplementados ao alimento, que atuam no intestino do hospedeiro, proporcionando o equilíbrio de sua microbiota intestinal. Estes atuam na exclusão competitiva de bactérias patogênicas, como fonte de nutrientes, como contribuição enzimática para a digestão, na melhora da resposta imune e efeitos antivirais, melhorando o desempenho zootécnico dos animais (Fuller, 1989; Balcazar et al., 2006). Krumenauer et al. (2014a) verificaram que o uso de probiótico em L. vannamei infectados por Vibrio parahaemolyticus produziu maior taxa de crescimento e sobrevivência e menor conversão alimentar. Assim como Souza et al. (2012), em F. brasiliensis, observaram maiores pesos finais e taxa de crescimento específico, além de menor concentração de Vibrio spp. com o uso de probiótico. Segundo Emerenciano et al. (2013) o probiótico natural do biofloco pode atuar contra Vibrio sp., pois a competição com as bactérias heterotróficas dominantes e bactérias nitrificantes limita o desenvolvimento Vibrio sp. A tendência de dominância de Vibrio diminui com o aumento das relações C: N (Panigrahi et al. 2018).

Entre os diversos tipos de aditivos utilizados, os prebióticos podem atuar como moduladores do muco intestinal, aumentando as vilosidades intestinais e microvilosidades, promovendo o desenvolvimento de bactérias saudáveis, reduzindo a colonização de espécies patogênicas, promovendo, assim, a resposta imunológica e impactando positivamente os índices zooteécnicos de peixes e camarões (Merrifield et al., 2010; Zhang et al., 2012; Sang et al., 2014). Os prebióticos mais comumente usados na aquicultura são fruto-oligossacarídeos (FOS), galacto-oligossacarídeos (GOS) e mananoligossacarídeos (MOS), polissacarídeos de inulina e $\beta$-glucanase (Song et al., 2014). Em estudo recente, a suplementação dietética com diferentes concentrações de manoproteínas $(0.02 \%, 0.08 \%$ e $0.12 \%)$ resultou em aumento na sobrevivência em $10 \%$ e na área superficial média do intestino médio de camarão (Rodrigues et al., 2018).

O sistema de bioflocos, por ser um modelo que utiliza menores unidades de cultivo, consequentemente, possibilita sua implementação em menores áreas, tornando possível uma maior eficiência produtiva e um melhor aproveitamento da área de forma mais sustentável, visto que a expansão da aquicultura, atualmente, se restringe a disponibilidade e aos custos de terra. Torna-se viável, assim, somado à redução do uso de água, a construção de unidades tanto junto à linha da costa quanto distantes da mesma, utilizando águas de baixa salinidade (Samocha et al., 2012). Segundo Krumenauer et al. (2014), a mesma água pode ser usada para vários ciclos de produção sem impacto negativo sobre o rendimento. Além disso, o sistema BFT apresenta maior biossegurança, maior estabilidade do sistema produtivo, aumento da produtividade, redução ou isenção das renovações de água, maior disponibilidade de alimento natural e menor impacto ambiental, sendo uma possível alternativa para produzir com menor risco (Wasielesky et al., 2006; Avnimelech, 2009; Krummenauer et al. 2011; Perez-Fuentes et al. 2013). Em contrapartida, deve-se considerar os maiores gastos com energia (aeradores) e maiores custos operacionais e de instalação, de forma a fazer deste um sistema economicamente viável. No entanto, há um ganho em sobrevivência, taxa de conversão alimentar, produtividade e previsibilidade dos resultados da safra (Poersch et al., 2012). Este sistema permite aumento da produtividade na ordem de 3 a 5 vezes, se comparado aos sistemas tradicionais (Poersch et al., 2012a). 


\section{CONSIDERAÇÕES FINAIS}

A qualidade da água é o aspecto de maior importância nos sistemas de cultivo da aquicultura, pois interferem diretamente nas respostas fisiológicas e no desempenho dos organismos aquáticos. O sistema de bioflocos traz, para o cultivo de camarão, uma grande vantagem ao proporcionar melhores condições de biossegurança, sanidade, sustentabilidade e melhor controle de qualidade de água. Este sistema possibilita um cultivo ambientalmente seguro, com menos ou nenhuma troca de água, e um aumento na produtividade, se mostrando uma ferramenta de extrema importância para a carcinicultura. Inúmeros estudos foram realizados e excelentes resultados foram obtidos, mas ainda existem muitas lacunas a serem exploradas e, portanto, pesquisas devem ser realizadas a fim de avaliar o sucesso efetivo deste sistema e de seu manejo.

\section{REFERENCIAS}

Ahmad, I.; Rani, A. B.; Verma, A. K.; Maqsood, M. Biofloc technology: an emerging avenue in aquatic animal healthcare and nutrition. Aquaculture International, v. 25, n. 3, p. 12151226, 2017.

Arana, L.V. Princípios químicos de qualidade da água em aquicultura, Editora UFSC, 133p, Florianópolis, 2002.

Arnold, S.J.; Sellars, M.J.; Crocos, P.J. \& Coman, G.J. An evaluation of stocking density on the intensive production of juvenile brown tiger shrimp (Penaeus esculentus). Aquaculture, v. 256, n. 1, p. 174-179, 2006.

Avnimelech, Y. Carbon/nitrogen ratio as a control element in aquaculture systems. Aquaculture, v. 176, n. 3, p. 227-235, 1999.

Avnimelech, Y. \& Ritvo, G. Shrimp and fish pond soils: processes and management. Aquaculture, v. 220, n. 1, p. 549-567, 2003.

Avnimelech, Y. Biofloc technology. A practical guide book. The World Aquaculture Society, Baton Rouge, 2009.

Avnimelech, Y. Biofloc Technology - A Practical Guide Book, 3. ed. The World Aquaculture Society, Baton Rouge: Louisiana, EUA, 2015.

Balcázar, J.L.; De Blas, I.; Ruiz-Zarzuela, I.; Cunningham, D.; Vendrell, D. \& Muzquiz, J.L. The role of probiotics in aquaculture. Vet Microbiol. v. 114, n. 3, p. 173-186, 2006.

Ballester, E.; Abreu, P.; Cavalli, R.O.; Emerenciano, M.; Abreu, L. \& Wasielesky, W. Effect of practical diets with different protein levels on the performance of Farfantepenaeus paulensis juveniles nursed in a zero exchange suspended microbial flocs intensive system. Aquac Nutr, v. 16, n. 2, p. 163-172, 2010.

Burford M.A.; Thompson P.J.; McIntosh R.P.; Bauman R.H. \& Pearson D.C. Nutrient and microbial dynamics in high-intensity, zero-exchange shrimp ponds in Belize. Aquaculture, v. 219, n. 1, p. 393-411, 2003.

Boyd, C.E. \& Teichert-coddington, D. Relationship between wind speed and reaeration in small aquaculture ponds. Aquac Eng, v. 11, n. 2, p. 121-131, 1992. 
Campos, S.S.; Silva, U.L.; Lúcio, M.Z.T.P.Q. L. \& Correia, E. S. Grow out of the Litopenaeus vannamei in microcosms fertilized with wheat bran without water exchange. Archivos de Zootecnia, v. 56, n. 214, p. 181-190, 2007.

Campos, B.R.; Miranda Filho, K.C.; D’Incao, F.; Poersch, L. \& Wasielesky, W. Toxicidade aguda da amônia, nitrito e nitrato sobre os juvenis de camarão-rosa Farfantepenaeus brasiliensis (Latreille, 1817) (Crustacea: Decapoda). Atlântica, v. 34, n. 1, p. 75-81, 2012.

Chan-Vivas, E., Edén, M. G., Maldonado, C., Escalante, K., Gaxiola, G., \& Cuzon, G. Does Biofloc Improve the Energy Distribution and Final Muscle Quality of Shrimp, Litopenaeus vannamei (Boone, 1883)?. Journal of the World Aquaculture Society, 2018.

Crab, R.; Avnimelech, Y.; Defoirdt, T.; Bossier, P.; Verstraete, W. Nitrogen removal techniques in aquaculture for a sustainable production. Aquaculture, v. 270, n. 1-4, p. 1-14, 2007.

Coman, G. J., Crocos, P. J., Preston, N. P., \& Fielder, D. The effects of temperature on the growth, survival and biomass of different families of juvenile Penaeus japonicus Bate. Aquaculture, v. 214, n. 1-4, p. 185-199, 2002.

De Schryver, P.; Crab, R.; Defoirdt, T.; Boon, N.; Verstraete, W. The basics of bio-flocs technology: the added value for aquaculture. Aquaculture, v. 277, n. 3-4, p. 125-137, 2008.

Duan, Y.; Wang, Y.; Zhang, J.; Xiong, D. Elevated temperature disrupts the mucosal structure and induces an immune response in the intestine of whiteleg shrimp Litopenaeus vannamei (Boone, 1931) (Decapoda: Dendrobranchiata: Penaeidae). Journal of Crustacean Biology, v. 38, n. 5, p. 635-640, 2018.

Emerenciano, M.; Ballester, E. L.; Cavalli, R. O.; Wasielesky, W. Effect of biofloc technology (BFT) on the early postlarval stage of pink shrimp Farfantepenaeus paulensis: growth performance, floc composition and salinity stress tolerance. Aquaculture International, v. 19, n. 5, p. 891-901, 2011.

Emerenciano, M.; Ballester, E. L.; Cavalli, R. O.; Wasielesky, W. Biofloc technology application as a food source in a limited water exchange nursery system for pink shrimp Farfantepenaeus brasiliensis (Latreille, 1817). Aquaculture research, v. 43, n. 3, p. 447-457, 2012.

Emerenciano, M.; Gaxiola, G.; Cuzon, G. Biofloc technology (BFT): a review for aquaculture application and animal food industry. In Biomass now-cultivation and utilization. InTech. 2013.

Emerenciano, M.; Cuzon, G.; Arévalo, M.; Gaxiola, G. Biofloc technology in intensive broodstock farming of the pink shrimp Farfantepenaeus duorarum: spawning performance, biochemical composition and fatty acid profile of eggs. Aquaculture Research, v. 45, n. 10, p. 1713-1726, 2014.

Emerenciano, M. G. C.; Martínez-Córdova, L. R.; Martínez-Porchas, M.; Miranda-Baeza, A. Biofloc technology (BFT): a tool for water quality management in aquaculture. In: Water Quality. InTech, 2017.

FAO, 2012. El estado mundial de la pesca y la acuicultura. Roma, FAO Information Division. 231 p.

FAO, 2016. El estado mundial de la pesca y la acuicultura. Roma, FAO Information Division. 213 p.

Froes, C.; Foes, G.K.; Krummenauer, D.; Ballester, E.; Poersch, L.H. \& Wasielesky, W. Fertilização orgânica com carbono no cultivo intensivo em viveiros com sistema de bioflocos do camarão branco Litopenaeus vannamei. Revista Atlântica, v. 34, n. 1, p. 31-39, 2012. 
Fuller, R. Probiotics in man and animals. J Appl Bacteriol, v. 66, n. 5, p. 365-378, 1989.

Furtado, P.S.; Poersch, L.H. \& Wasielesky, W. Effect of calcium hydroxide, carbonate and sodium bicarbonate on water quality and zootechnical performance of shrimp Litopenaeus vannamei reared in bioflocs technology (BFT) systems. Aquaculture, v. 321, n. 1, p. 130-135, 2011.

Furtado, P.S.; Serra, F.P.; Gaona, C.A.P.; Poersch, L.H. \& Wasielesky, W. Cultivo de camarões marinhos com tecnologia de bioflocos: A influência da Alcalinidade, pH e CO2. Panorama da Aquicultura, p 44-53, 2013.

Furtado, P.S.; Poersch, L.H. \& Wasielesky, W. The effect of different alkalinity levels on Litopenaeus vannamei reared with biofloc technology (BFT). Aquac Int, v. 23, n. 1, p. 345-358, 2015.

Gaona, C.A.P.; Poersch, L.H.; Krummenauer, D.; Foes, G.K. \& Wasielesky, W. The effect of solids removal on water quality, growth and survival of Litopenaeus vannamei in a biofloc technology culture system. International Journal of Recirculating Aquaculture, Vol. 12, 54-73, 2011.

Gaona, C. A. P.; de Almeida, M. S.; Viau, V.; Poersch, L. H.; Wasielesky Jr, W. Effect of different total suspended solids levels on a Litopenaeus vannamei (Boone, 1931) BFT culture system during biofloc formation. Aquaculture Research, v. 48, n. 3, p. 1070-1079, 2017.

Hargreaves, J. A. Photosynthetic suspended-growth systems in aquaculture. Aquac Eng, v. 34, n. 3, p. 344-363, 2006.

Hewitt, D. R.; Duncan, P. F. Effect of high water temperature on the survival, moulting and food consumption of Penaeus (Marsupenaeus) japonicus (Bate, 1888). Aquaculture Research, v. 32, n. 4, p. 305-313, 2001.

Krummenauer, D.; Wasielesky W.; Cavalli, R.O.; Peixoto, S. \& Zogbi, P.R. Viabilidade do cultivo do camarão-rosa Farfantepenaeus paulensis (Crustácea, Decapoda) em gaiolas sob diferentes densidades durante o outono no sul do Brasil. Cienc Rural, v. 36, n.1, p. 252-257, 2006.

Krummenauer, D. Estratégias para o cultivo de Litopenaeus vannamei (Boone, 1931) no extremo sul do Brasil. Dissertação de Mestrado, Programa de Pós-graduação em Aquicultura, Universidade Federal de Rio Grande, Rio Grande, 2008.

Krummenauer, D.; Cavalli, R.O.; Poersch L.H. \& Wasielesky, W. Superintensive Culture of White Shrimp, Litopenaeus vannamei, in a Biofloc Technology System in Southern Brazil at Different Stocking Densities. J World Aquac Soc, v. 42, n. 5, p. 726-733, 2011.

Krummenauer D., Samocha T., Poersch L. H., Lara G. R., Wasielesky W.. Effect of water reuse on the culture of Pacific White Shrimp Litopenaeus vannamei in BFT system. J World Aquac Soc, v. 45, n. 1, p. 3-14, 2014.

Krummenauer, D.; Poersch, L.H.; Romano, L.A.; Lara, G.R.; Encarnação, P. \& Wasielesky, $\mathrm{W}$. The effect of probiotics in a Litopenaeus vannamei biofloc culture system infected with Vibrio parahaemolyticus. Journal of Applied Aquaculture, v. 26, n. 4, p. 370-379, 2014a.

Lara, G., Krummenauer, D., Abreu, P. C., Poersch, L. H., \& Wasielesky, W. The use of different aerators on Litopenaeus vannamei biofloc culture system: effects on water quality, shrimp growth and biofloc composition. Aquac Int, v. 25, n. 1, p. 147-162, 2017. 
Lopes D.L.A.; Peixoto S.R.M.; Wasielesky W. \& Ballester E.L.C. Análise comparativa da criação dos camarões-rosa Farfantepenaeus brasiliensis e Farfantepenaeus paulensis criados em gaiolas em ambiente estuarino. Cienc Rural, v. 39, n. 5, 2009.

Maicá, P. F.; De Borba, M. R.; Wasielesky Jr, W. Effect of low salinity on microbial floc composition and performance of Litopenaeus vannamei (Boone) juveniles reared in a zero water-exchange super-intensive system. Aquac Res, v. 43, n. 3, p. 361-370, 2012.

Manan, H.; Moh, J. H. Z.; Kasan, N. A.; Suratman, S.; Ikhwanuddin, M. Identification of biofloc microscopic composition as the natural bioremediation in zero water exchange of Pacific white shrimp, Penaeus vannamei, culture in closed hatchery system. Applied Water Science, v. 7, n. 5, p. 2437-2446, 2017.

Merrifield, D. L., Dimitroglou, A.; Foey, A.; Davies, S. J.; Baker, R. T.; Bøgwald, J., ...; Ringø, E. The current status and future focus of probiotic and prebiotic applications for salmonids. Aquaculture, v. 302, n. 1-2, p. 1-18, 2010.

Natori, M.N.; Sussel, F.R.; Santos, E.C.B.; Previero, T.C.; Viegas, E.M.M. \& Gameiro, A.H. Desenvolvimento da Carcinicultura Marinha no Brasil e no mundo: Avanços tecnológicos e Desafios. Informações econômicas, v. 41, n. 2, p. 61-73, 2011.

Otoshi, C.A.; Naguwa, S.S.; Falesch, F.C. \& Moss, S.M. Shrimp behavior may affect culture performance at super-intensive stocking densities. Global Aquac Adv, v. 10, n.2, p. 67-69, 2007.

Panigrahi A, Sundaram M, Ravichandran P, Gopal C, (2014) Microbial soup-Eco based approach for shrimp culture and management. CIBA (Indian Council of Agricultural Research) ENVIS Centre Newsletter, v. 12, p. 2. 2 Apr-Jun 2014.

Panigrahi, A.; Saranya, C.; Sundaram, M.; Kannan, S. V.; Das, R. R.; Kumar, R. S.; ...; Otta, S. K. Carbon: Nitrogen (C: N) ratio level variation influences microbial community of the system and growth as well as immunity of shrimp (Litopenaeus vannamei) in biofloc based culture system. Fish $\mathcal{E}$ shellfish immunology, v. 81, p. 329-337, 2018.

Pérez-Fuentes, J. A.; Pérez-Rostro, C. I.; Hernández-Vergara, M. P. Pond-reared Malaysian prawn Macrobrachium rosenbergii with the biofloc system. Aquaculture, v. 400, p. 105-110, 2013.

Pinheiro, W.C.; Filho, J.A. \& Maracajá, P.B. Efeitos climáticos e físico-químicos sobre a biologia do Litopenaeus vannamei cultivado em viveiro. Rev Verde Agroecologia Desenvolv Sustent, v. 2, n. 2, p. 142-150, 2007.

Poersch, L.H.; Foes, G.K.; Krummenauer, D.; Almeida, M.; Furtado, P.S. \& Wasielesky, W. Bioflocos: Uma alternativa econômica viável para produtores de camarão em viveiros. Panorama da Aquicultura, p 36-41, 2012.

Poersch, L.H.; Foes, G.K.; Krummenauer, D.; Romano, L.A. \& Wasielesky, W. Bioflocos: uma alternativa para camarões saudáveis. Panorama da Aquicultura, v.22, n.130, p 28-37, 2012a.

Ponce-Palafox, J.; Martinez-Palacios, C.A. \& Ross, L.G. The effects of salinity and temperature on the growth and survival rates of juvenile white shrimp Penaeus vannamei, Boone, 1931. Aquaculture, v. 157, n. 1-2, p. 107-115, 1997.

Preto, A.; Cavalli, R.O.; Pisseti, T.; Abreu, P.C \& Wasielesky, W. Efeito da densidade de estocagem sobre o biofilme e o desempenho de pós-larvas do camarão-rosa Farfantepenaeus paulensis cultivado em gaiolas. Cienc Rural, v. 35, p. 1417-1423, 2005. 
Ray, A.J.; Lewis, B.L.; Browdy, C.L. \& Leffler, J.W. Suspended solids removal to improve shrimp (Litopenaeus vannamei) production and an evaluation of a plant-based feed in minimal-exchange, superintensive culture systems. Aquaculture, v. 299, n. 1, p. 89-98, 2010.

Ray, A. J.; Dillon, K. S.; Lotz, J. M. Water quality dynamics and shrimp (Litopenaeus vannamei) production in intensive, mesohaline culture systems with two levels of biofloc management. Aquacultural Engineering, v. 45, n. 3, p. 127-136, 2011.

Ray, A.J. \& Lotz, J.M. Comparing salinities of 10, 20, and 30\%o in intensive, commercialscale biofloc shrimp (Litopenaeus vannamei) production systems. Aquaculture, v. 476, p. 29-36, 2017.

Rodrigues, M. S.; Bolívar, N.; Legarda, E. C.; Guimarães, A. M.; Guertler, C.; do Espírito Santo, C. M.; ...; do Nascimento Vieira, F. Mannoprotein dietary supplementation for Pacific white shrimp raised in biofloc systems. Aquaculture, v. 488, p. 90-95, 2018.

Samocha, T.M.; Schveitzer, R.; Krummenauer, D. \& Morris, T. Recent Advances in SuperIntensive, Zero-Exchange Shrimp Raceway Systems. Global Aquac Adv, v. 15, n. 6, p. 70-71, 2012.

Sampaio, L.A.; Tesser, M.B. \& Wasielesky, W. Avanços da maricultura na primeira década do século XXI: piscicultura e carcinocultura marinha. Rev Bras Zootec, v. 39, p. 102-111, 2010.

Sang, H. M.; Kien, N. T.; Thanh Thuy, N. T. Effects of dietary mannan oligosaccharide on growth, survival, physiological, immunological and gut morphological conditions of black tiger prawn (Penaeus monodon Fabricius 1798). Aquaculture nutrition, v. 20, n. 3, p. 341-348, 2014.

Schveitzer, R., Arantes, R., Costódio, P. F. S., do Espírito Santo, C. M., Arana, L. V., Seiffert, W. Q., \& Andreatta, E. R. Effect of different biofloc levels on microbial activity, water quality and performance of Litopenaeus vannamei in a tank system operated with no water exchange. Aquacultural Engineering, v. 56, p. 59-70, 2013.

Serra, F.P.; Gaona, C.A.; Furtado, P.S.; Poersch, L.H. \& Wasielesky, W. Use of different carbon sources for the biofloc system adopted during the nursery and grow-out culture of Litopenaeus vannamei. Aquac Int, v. 23, n. 6, p. 1325-1339, 2015.

Silva, A.F.; Lara, G.R.; Ballester, E.D.; Krumennauer, D.; Abreu, P.C. \& Wasielesky, W. Efeito das altas densidades de estocagem no crescimento e sobrevivência de Litopenaeus vannamei na fase final de engorda, cultivados em sistemas de bioflocos (BFT). Ciênc Anim Bras, v. 14, n. 3, p. 279-287, 2013.

Souza, D.M.; Suita, S.M.; Leite, F.P.L.; Romano, L.A.; Wasielesky, W. \& Ballester, E.L.C. The use of probiotics during the nursery rearing of the pink shrimp Farfantepenaeus brasiliensis (Latreille, 1817) in a zero exchange system. Aqua. Res., v. 43, n. 12, p. 1828-1837, 2012.

Souza, D.M.; Suita, S.M.; Romano, L.A.; Wasielesky, W. \& Ballester, E.L.C. Use of molasses as a carbon source during the nursery rearing of Farfantepenaeus brasiliensis (Latreille, 1817) in a Biofloc technology system. Aqua. Res., v. 45, n. 2, p. 270-277, 2014.

Viau, V.E.; Souza, D.M.; Rodríguez, E.M.; Wasielesky, W.; Abreu, P.C. \& Ballester, E.L. Biofilm feeding by postlarvae of the pink shrimp Farfantepenaeus brasiliensis (Decapoda, Penaidae). Aquac Res, v. 44, n. 5, p. 783-794, 2013.

Wang, C.; Pan, L.; Zhang, K.; Xu, W.; Zhao, D.; Mei, L. Effects of different carbon sources addition on nutrition composition and extracellular enzymes activity of bioflocs, and digestive enzymes activity and growth performance of Litopenaeus vannamei in zeroexchange culture tanks. Aqua. Res., v. 47, n. 10, p. 3307-3318, 2016. 
Wang, F. I., \& Chen, J. C. The immune response of tiger shrimp Penaeus monodon and its susceptibility to Photobacterium damselae subsp. damselae under temperature stress. Aquaculture, v. 258, n. 1-4, p. 34-41, 2006.

Wasielesky, W.; Atwood, H.; Stokes, A. \& Browdy, C.L. Effect of natural production in a zero exchange suspended microbial floc based super-intensive culture system for white shrimp Litopenaeus vannamei. Aquaculture, v. 258, n. 1, p. 396-403, 2006.

Wasielesky, W; Atwood, H.I.; Stokes, A. \& Browdy, C.L. Efeito do pH na sobrevivência e crescimento do camarão-branco Litopenaeus vannamei em cultivos superintensivos. In Livro de Resumos AquaCiência, Bento Gonçalves, Brasil. 2006a

Zhang, J., Liu, Y., Tian, L., Yang, H., Liang, G., \& Xu, D. Effects of dietary mannan oligosaccharide on grow th performance, gut morphology and stress tolerance of juvenile Pacific white shrimp, Litopenaeus vannamei. Fish $\mathcal{E}$ shellfish immunology, v. 33, n. 4, p. 1027-1032, 2012. 